\title{
Efficacy Study
}

National Cancer Institute

\section{Source}

National Cancer Institute. Efficacy Study. NCI Thesaurus. Code C49666.

A study of the relative therapeutic efficacy of treatment of a disease. Usually this is a Phase II or III study. 